\title{
The Itinerant Curriculum as an Alternative Curriculum Pathway in Nigerian Higher Education
}

\author{
Kehdinga George Fomunyam \\ Teaching and Learning Development Centre, Mangosuthu University of Technology, South Africa
}

Received May 31, 2020; Revised September 4, 2020; Accepted October 29, 2020

\section{Cite This Paper in the following Citation Styles}

(a): [1] Kehdinga George Fomunyam, "The Itinerant Curriculum as an Alternative Curriculum Pathway in Nigerian Higher Education," Universal Journal of Educational Research, Vol. 8, No. 12B, pp. 8304-8312, 2020. DOI: 10.13189/ujer.2020.082635.

(b): Kehdinga George Fomunyam (2020). The Itinerant Curriculum as an Alternative Curriculum Pathway in Nigerian Higher Education. Universal Journal of Educational Research, 8(12B), 8304-8312. DOI: 10.13189/ujer.2020.082635.

Copyright $\mathrm{C} 2020$ by authors, all rights reserved. Authors agree that this article remains permanently open access under the terms of the Creative Commons Attribution License 4.0 International License

\begin{abstract}
The quality of university graduates and research outputs in relation to the expectations of local employers of labour and the organisations that should commercialise research findings, are far from fulfilling the goals set by the educational system and Nigerian society as a whole. This paper examines the imperative for an urgent rethink on the curriculum of Nigerian higher institutions in order to keep pace with the needs of society. This study explores and highlights the need to deconstruct and reconstruct the curriculum to ensure it is tailored to reflect the specific needs of the country. The argument is that a shift away from the current curriculum system can improve the educational system and society as a whole. The focus is on the itinerant curriculum as an alternative that will steer the educational system in the right direction by adopting curriculums that align with and are tailored to suit the particular and inherent structure, system and needs of the Nigerian society. It explores the adoption of a mixed and more indigenous curriculum centered on the Nigerian situation, goals and objectives as opposed to the predominantly Eurocentric curriculum in practice in Nigerian institutions and across Africa. This study proposes that curriculum researchers adopt a contributory system where students and professionals have an input in designing course curriculums to reflect real life occupational situations and solutions.
\end{abstract}

Keywords Itinerant Curriculum, Higher Education, Nigeria, Curriculum

\section{Introduction}

Nigeria's underdevelopment has often been linked to lack of investment in human development and problems associated with educational reforms, i.e. churning out graduates into the 21 st-century knowledge economy which sees practicality of acquired knowledge as the utmost form of learning than other forms of economy which intensely focus on abstract knowledge acquisition (Agwu, 2018).

Like many developing economies, Nigeria faces ominous educational challenges and there is no will within the political class to address them. The question is: how do we develop an educational curriculum that will pragmatically identify how to improve the Nigerian student in the Nigerian society and prepare them for the organisations of tomorrow? Two challenges are evident in this regard, first is the issue of an ineffective and predominantly westernized curriculum put in place by British colonialists, and the second is centred on the knowledge of those who impart the curriculum contents to the next generation of learners. Eurocentrism is the practice of focusing on European culture or history to the exclusion of a wider view of the world; implicitly regarding European culture as pre-eminent. This is the case with most of Africa's curriculum, including the Nigerian educational system where the curriculum across all levels are a result of the epistemicide where our content is predominantly ignored in favour of a Westernized, specifically British-inherited curriculum (LBS Insight, 2019).

Nigerian education regulators ensure that all institutions strictly comply and teach moribund and archaic curriculum 
contents, thereby suppressing the cognitive growth of the nation's future leaders who are required to think outside the box. Emphasis are centred more on the acquisition of abstract terms and not on the significant impacts of the content on students' ability to apply the terms in problematic situations.

This has necessitated the demand for an itinerant curriculum where Nigerian content will be inculcated and feature strongly in the curriculum for better education that will more effectively equip our youth with the knowledge and skills needed to address problems peculiar to our society.

Bennett (2014) defines epistemicide is a systematic destruction of any indigenous knowledge base, such that the perpetrator doesn't believe in fusion or exchange of knowledge, and completely disregards the victims' knowledge. It is the killing of knowledge. Fataar \& Surbreenduth (2016) describe epistemicide as a "metaphor for the epistemological marginalisation, or evisceration of African-centered intellectual traditions in formal education". They posit that epistemicide is as a result of "constant hegemonic western science model of knowledge construction, production and consumption that circulates within education discourse and practice on the African continent as relevant, valuable and best practice". The educational and curriculum practices of the colonial masters were devoid of the cultural epistemologies of the African people. In response to this, several scholars have called for different solutions to ensure the relevance of the curriculum used in higher education institutions in Africa. Some of which are; a new ecology of knowledge (Jupp and Espinosa-Dulanto (2017), the defeat and replacement of scientific knowledge by an ecology of knowledge (Sousa Santos, 2003), deconstruction of the academic curriculum (Higgs, 2002), standardization in African higher education (Woldegiorgis, 2013) and the decolonisation of the curriculum (Woolman, 2001; Kehdinga \& Damtew, 2017; Padayachee et al., 2018). Drawing from the works of Santos (2008), Joao Paraskeva (2011) proposes an itinerant curriculum theory to fight against epistemicide.

This paper proposes the introduction of an itinerant curriculum to ensure that knowledge centred on localized situations are prioritized in Nigerian higher institutions, thereby better equipping Nigerian graduates with the knowledge and tools needed to embark on economic restructuring, resolving societal challenges and eventually rebuilding the economy. The following sections highlight and assess the higher education situation in Nigeria, the literature review provides an insight on the itinerant curriculum as opined by various scholars and further down are outlined the benefits of adopting the itinerant curriculum.

\section{Higher Education in Nigeria}

Between 1980 and 2019, the number of recognized universities in Nigeria has grown tenfold from 16 to 174 universities. According to the official website of the National University Commissions (NUC), Nigeria presently has 43 Federal Universities as well as dozens of teaching hospitals and colleges which are under the direct purview of the NUC, 52 State Universities administered and financed by the state government, and 79 Private Universities. For the first few decades of growth, higher education capacity building was primarily in the public sector, driven by Federal and State governments. More dramatic growth occurred beginning in the late 1990s, when the Nigerian government began to encourage the establishment of private universities.

In Nigeria's current private sector-led economy, university graduates cannot meet employers needs and are grossly under skilled and underqualified. Graduates are loafers, job seekers, as against graduate workers and job creators (Makinde, 2005:62). Out of 130,000 graduates that pass out every year from Nigerian higher institutions, only $13,000(10 \%)$ of them are able to secure employment (Gyamfi, 2006:41). It does appear there is a dearth of the ideas of the founding fathers (Nwakanma, 2006). On account of current dysfunctionality of most Nigerian universities' graduates and research outputs, the higher education system fulfils only a little of the vision for their establishment. There is a yawning gap between the curriculum of Nigerian university education system and the roles its graduates are expected to play in the society making it imperative to rethink the educational curriculum so as to improve the functionality of the system. This is majorly due to the fact that the present curriculum in use in Nigerian HEIs was inherited from the British colonial masters, is predominantly Eurocentric and was neither designed for, nor suitable for the Nigerian situation socially, economically, culturally or in any other form.

The Nigerian educational system requires urgent revalidation and standardisation in light of the changing global tides. Let us take a cursory look into three important educational constructs and put them into consideration, viz: how are Nigerian schools funded? How are the teachers trained? And what is the content of the curriculum being dished out to these neophyte learners in their various classrooms? Therefore, in accordance with global best practices, there is need for the holistic overhaul of the curriculum in terms of educational practices, entrance routes to different courses of study, credential requirements in relation to the learning objectives and outcomes, options of continued training, codes of teaching and the evaluation of the teaching requirements for various courses (Agwu, 2018).

\section{Evaluating the Effectiveness of Nigeria's Higher Education Curriculum}

The academic curriculum in Nigeria's educational institutions - nursery, primary, secondary, and tertiary 
were passed down by the British colonial masters more than sixty years ago and are far behind in civilisation, development, and innovation. Most worrisome is the tenacity with which the education regulatory bodies in Nigeria, notably West African Examination Council (WAEC) and National Examination Council (NECO), National Universities Commission (NUC), and Joint Admissions and Matriculation Board (JAMB) are pushing for a holistic usage and application of these Eurocentric, not-fit-for-purpose and out-dated contents that neither serve the public nor the business world and have been implemented for decades on end. Other economies including Britain have since moved on to improve their curriculum with current and practical content which have ensured the production of innovative and highly creative graduates. In Nigeria, there is an over-reliance on paper qualification as opposed to the skills and can-do attitude of an individual. Gwaravanda (2019), posits then that the knowledge passed across to students is tantamount to a waste of time and resources, because knowledge attained through a predominantly Eurocentric and obsolete curriculum is neither valued in the current dispensation of organisational development, nor capable of preparing these learners for future challenges or tasks. The outdated curriculum has made it difficult for these graduates to be employable and therefore requires that they are retrained to fit into various organisations. The African university education system is currently dominated by Western epistemology where the analytic model of knowledge is being used. The model relies on the definition of knowledge as justified true belief. This definition of knowledge is not only foreign to the African university but it also has implications that are inconsistent with the African ways of knowing. The Western definition of knowledge excludes social epistemology that is fundamental in the African knowledge paradigm. African knowledge systems validate knowledge through the community. The African university education finds itself in the paradox of mimicry and are currently dualized along Eurocentric thought (which is the dominant one) and weak Africanized curricula which blends both Eurocentric thinking and African indigenous knowledge system. However, it has to be pointed out that African knowledge systems contribute an insignificant part in the weak Africanized curriculum.

Eurocentric epistemology creates contradictions, uncertainties, and dilemmas. Eurocentric epistemology assumes a "universalistic, neutral, objective point of view" [2]. Following such epistemological underpinnings, African universities have used universality, objectivity, and neutrality to define and influence content of the curriculum without the problematization of these concepts. "Universality" hides the subject and claims knowledge applicability "always and everywhere" to borrow the Kantian phrase. Critics of Eurocentric thinking have argued that "universality" is a myth $[2,3,4]$. The aspect of location should therefore be included in knowledge claims without assuming Kantian universality. (Gwaravanda,2019).

The prejudice of those who had colonial education was strong and, for a long time, frustrated the emergence of a coherent Nigerian indigenous educational policy. As Abdu Moumouni (1968:42) observed, opposition to the new philosophy stemmed from: a kink of panic because of the difficulties a profound change in the educational system would entail, and from conviction that the current system inherited from colonialism 'isn't that bad', it 'proved itself', 'it educated us', and so on. Also, neo-colonial forces of Europe and America were actively at work, especially as the pioneer key administrators and staff were mainly Europeans, Americans or those they had trained in their countries. Thus, while a university is anchored on and grows on the social, economic, political, ethical, and legal environment of its society, Nigerian universities have swallowed in its entirety the external standards of Europe and America (Umeh, 1985:120). The Nigerian university graduate, like the Nigerian graduate of the British university, is incapable of giving meaningful and productive leadership in his fields in Nigeria, whereas British university produces British leaders, who play major roles in shaping passions, ideologies and societal visions, in all fields of human endeavour in Britain. The difference is that education is in proper context in developed countries, but out of context in Nigeria. African universities are alien institutions in their own land. Their curriculum is designed for white-collar jobs.

According to Ali Mazrui (1993:119), The African university was conceived primarily as a transmission belt for Western high culture, rather than a workshop for the transfer of Western high skills. Nigerian universities became nurseries for a Westernised black intellectual aristocracy. Graduates of Ibadan, Dakar, Makerere acquired Western social tastes more readily than Western organization skills. Those graduates became steeped in Western consumption patterns rather than Western productive techniques (Eneh, 2015). It is important to review the current academic curricula in order to synthesize the data with the quality of teaching and learning in public and private schools in the nation. Furthermore, the admission standards for course requirements need to be enhanced in order to decide whether the requirements are capable of determining the level of futuristic impacts on the academic excellence of the students and their relevance. Current events in the global arena, especially the shift in technological paradigms to new constructs such as artificial intelligence, robotics engineering and different emerging concepts and terms in various fields are factors to be considered in redesigning befitting new school curricula for Nigerian institutions. It is important to consider societal trends to ensure that the relevance of knowledge acquired in institutions are equated with real and practical applications, 
as there is need to showcase the applications of the acquired theory in the industries when students graduate and are conferred with degrees.

Again, the United Kingdom after whose curriculum Nigeria's is modelled, operate a capitalist economic system while Nigeria operates a mixed economic system, there are, therefore, underlying fundamental differences in policy, financing and ideology that makes the curriculum unsuitable for the Nigerian situation.

Therefore, in accordance with global best practices, there is need for the holistic overhaul of the curriculum in terms of educational practices, entrance routes to different courses of study, credential requirements in relation to the learning objectives and outcomes, options of continued training, codes of teaching and the evaluation of the teaching requirements for faculty, tutors or teachers. All these must be tailored towards ensuring that students attain mastery of the subject matter being taught and not the usual rote learning system. The step by step process will involve defining the educational challenges in the Nigerian system and then evaluating the different options available to ameliorate these challenges in line with doable alternatives. Education with a quality curriculum is the foundation on which a quality country will thrive and stand shoulder to shoulder with other countries (LBS Insight, 2019).

\section{Literature Review}

The search for a more inclusive and effective curriculum system saw a few scholars proposing various theories, including Paraskeva's Itinerant Curriculum Theory (ICT), which is popular for advocating for a 'mixed curricula approach' as opposed to the predominantly Eurocentric curriculum currently utilized in Nigeria. A few curriculum scholars have shared their thoughts on Paraskeva's theory.

According to Deleuze \& Guattari (1987) ICT attempts to create an itinerant path to address a problem. In so doing, it faces undesirable yet unavoidable, and needed, black holes. ICT is an unblemished claim against dominant multiculturalist forms that are "Eurocentric, a prime expression of the cultural logic of national or global capitalism, descriptive, apolitical, suppressing power relations, exploitation, inequality and exclusion" (Sousa Santos, 2007, pp. xxiii - xxiv), which have been legitimizing a monoculture of scientific knowledge that needs to be defeated and replaced by an ecology of knowledge (Sousa Santos, 2003). Jupp and Espinosa-Dulanto (2017) do not speak euphemistically when they denounce 'the erroneous tendencies' feeding and 'eugenicizing' multicultural foundations. They denounce multiculturalism as "a United Statesian and Anglophone project that is often universalized in unspoken ways" (p. 24). A new ecology of knowledge is necessary as a way to overcome both epistemicides and curriculum theories and perspectives that are sustained by the belief in the aprioristic superiority of some knowledge. Paraskeva's itinerant curriculum theory provides a way to think about curriculum from the perspective of the ecology of knowledge and South-North dialogue, it also contributes to curriculum and everyday school life studies. (p. 3). Itinerant curriculum shows, Oliveira (2017) argues, how the struggle for an ecology of knowledge cannot be detached from the yoke of the coloniality of knowledge, denouncing how previous multicultural curriculum projects were necessarily non-emancipatory and undeniably and profoundly regulatory.

Itinerant curriculum theory, in Oliveira's (2017) take, points out the responsibility of educators and curriculum theorists in understanding the task of curriculum studies in its relationship with daily school practices. Moreira (2017) argues ICT is the just theory that will promote "the decolonization of university practices and teacher education programs" (p. 9), a counter theory that places bilingualism as the trump card towards emancipatory praxis. ICT, Moreira (2017) claims, “does make sense and serves a more inclusive and more democratic education by helping to deterritorialize prevailing epistemologies" (p. 9). It 'confronts and throws' the subject to a permanently unstable question of 'what is it to think?'

An itinerant curriculum challenges book worship (Tse Tung, 2007, p. 45). It also encourages one to pay attention to the multiplicity of forms to read the wor(l)d and attempts to help us think in another form of being. It is a clarion call to challenge curriculum epistemicides by engaging fully in the complex struggle for social and cognitive justice. It is also a call to decolonize the 'decolonized.' Süssekind (2017) states: ICT, it follows, drives at denouncing and defeating the epistemicide produced and legitimized by the Global North and the northern intellectuals within the Global South. Such a conceptual framework raises crucial issues of whether the field of curriculum studies is a machinery for epistemicide and how radical critical theories can be both 'epistemicidal' and progressive simultaneously. (pp. 1-2). It is a claim for a just theory, a claim for a just science. It is possible for an itinerant curriculum theory - which we argue is the best path for critical progressive curriculum scholars - not only to grasp precious concepts and dynamics, such as hegemony, ideology, power, social emancipation, class, race, and gender in the complex age of globalization (Sousa Santos, 2008) or globalisms, but also to better (re)address the towering questions of curriculum, starting with the one asked by Counts in the last century: Dare the Schools Build a New Social Order?

The itinerant curriculum is an 'anti-bunker approach' (cf. Gil, 2009), one that promises a better perception and respect for epistemological diversity. Price (2017) states that ICT, provides insight into the affairs of teacher education, providing the tools to unpack the meanings behind the official, white paper reports regarding the imagined new teacher, or neoliberal teacher. Itinerant 
curriculum questions linguistic imperialism as portrayed by English and other Western imperial languages. It also challenges the way science has been defined and legitimized based on the cultural politics of academic writing, which are not only social formulas but also legitimize 'the modern epistemicidium' and are thus real obstacles to social and cognitive justice.

It is undeniably a call for a new never stable gathering epistemological point. Süssekind (2017) alerts us to how itinerant curriculum challenges "both hegemonic and specific counterhegemonic curriculum traditions that ended up contributing to an abyssality" (p. 9), an abyssal line that "pervades curriculum common sense, prescribes acceptable and non-acceptable ways of existing and thinking in the 'to-do curriculum' of results, and devises a eugenic panopticon that helps to establish the hegemonic logic of capital" (ibid).

An itinerant curriculum helps us to better rethink our collective responsibilities in the struggles against epistemicides, against social and cognitive justice. An itinerant curriculum, because it is deterritorialized and mobile, leads us to think about the responsibility of curriculum studies researchers in the struggle against epistemicides and modern abyssal thinking (Santos, 2010). It provides a means of overcoming epistemicides that split social realities and knowledge into two realms, existence and the abyss by resizing the role of hegemonic Global North traditions of scientific knowledge and also counterhegemonic traditions. Everything on one side of the line is understood as valid knowledge, and on the other side lie knowledge and social practices that are not recognized as a reality and are produced as non-existent. Paraskeva (2011) proposes that " $[t]$ he new itinerant curriculum theory will challenge one of the fundamental characteristics of abyssal thinking: the impossibility of co-presence of the two sides of the line" (p. 188).

Adopting this new understanding of the curriculum creation process enables us to overcome the formalist perspective that defines curricula only as a fixed and completed product. Moreover, doing so introduces us to the discussion of curricular theoretical production, starting from the notion that these are processes, full of dynamism and, therefore, of mutability. The unveiling of these daily created curricula appears, therefore, as fundamental to paving the way for the appearance of this everyday curriculum creation, potentiating the fights against the scientific discourses that disqualify schools, their subjects, and their knowledge. It also allows for the demonstration of the falsity of the ideas that the hegemonic curriculum fragmentation is real or that different knowledge circulating in schools can be separated, classified, and hierarchized. Many practices and procedures are beyond those which lazy reason has been able to see and study. They are the contents that contribute to the maturing work of the notion of curriculum as a daily creation and to the research in/for/with everyday school life. These lines of inquiry seek to unveil those practices and procedures, in the process, learning about what happens and is made in the course of everyday school life. In turn, this opens doors for us to realize what is emancipatory in such curricula, what practiced utopias (Oliveira, 2003) emerge from innovations, and can be potentiated from it. In other words, we are able to perceive the changes that can be conceived of, responsibly, for our schools and curriculum theories from the perspective of this dialogue between curricular theories and practices that we identify with the proposal of Paraskeva.

\section{Benefits Linked to adopting an Itinerant Curriculum in Nigerian HEIs}

Research has shown a change in curriculum is likely to help students succeed. Learning about their history and culture will increase students' confidence and self-awareness in a way that will help them seek to achieve more and be better for themselves and society. To become productive citizens within and beyond the school, students also need positive mind sets about self and school, along with social awareness and responsibility (Stafford-Brizard, 2016).

Research has further shown that for any society to grow to meet its desired development, quality must be added to the educational sector (Akoojee \& Nkomo, 2008). Education Indicators in Focus (2013), states that: "Education can bring significant benefits to the society". Adopting the itinerant curriculum will improve the quality of tertiary education in Nigeria and by extension, the economy.

The level of education of a nation determines the level of development that is experienced (Mitra, 2011). Statistics released by Basic Education Coalition (2014) asserts that education is essential for poverty reduction and economic growth and the itinerant curriculum offers thorough localized education, equipping the youth with better knowledge for tackling peculiar economic hurdles that the westernized Eurocentric curriculum has woefully failed to resolve for decades.

Nigerian HEIs have a poor track record in terms of result-oriented research, with very little inventiveness or innovation to show for their work. Adopting an itinerant curriculum opens doors to new levels of research that will yield results that will likely place Nigerian HEIs at par with the rest of the world. deterritorialized curriculum theory implies a commitment to fight for a different research platform, one that pushes research to a "level of instability, not stability, generating concepts also, in itself, unstable" (O'Brien \& Penna, 1999, p. 106). In doing so, a deterritorialized curriculum theory increasingly becomes an itinerant theory, a theory of non-spaces (Auge, 2003). In essence, as Gough (2000) claims, one needs to assume a rhizomatous approach that sees reality beyond dichotomies, beyond beginnings and endings; an approach that breeds 
from the multiplicity of immanent platforms and, from its centreless and periphery less position, defies clean knowledge territories (DeLeuze \& Guattari, 1987; Eco, 1984).

Adopting this curriculum will help empower schools and promote social equality. According to Paraskeva, the struggle for curriculum justice which is a struggle for social justice implies a struggle for cognitive justice. This is one of the pillars of Paraskeva's deterritorialized ICT. He also claims that the itinerant curriculum seeks to empower schools better and challenge savage social inequalities (Kozol, 1992). It would also provide the proper political tools to - read the word and the world (Freire, 1998), and would challenge the pedagogy of the big lies and the positivist trap that has been dominating the educational apparatus (Macedo, 2006, pg. 14).

\section{The Itinerant Curriculum as an Alternative for Nigeria's HEIs}

The call for a struggle of "alternative" knowledge birthed several new ideas among scholars eager to explore and offer up solutions to the ineffective colonial education system utilized in African countries. Key among these theories is Paraskeva's Itinerant Curriculum Theory (ICT), which garnered a lot of attention for its simplicity and the likelihood of ease in implementation across countries. The itinerant curriculum emphasizes the exploration of issues related to everyday school-life and curriculum and providing solutions to related problems in different schools in localized settings. Its tenets are built around the idea that the curriculum should embrace and reflect a country's specific values, culture, history and ideas for only then can students be properly educated and equipped to provide solutions to the challenges faced in their indigenous society. The solution to a society's problem is inherent and ingrained in its very fabric and one can only proffer solutions to a society's problems when one has a good grasp of its history and workings. Simply put - you have to understand its history and root cause to be properly equipped to solve a challenge. Wholly Westernised solutions cannot adequately address Nigeria's challenges. ICT values not just the need to see and review, it claims a future-itinerary - path and justifies why we need a critical itinerant approach. It is a theory of translation that attempts to prevent the "reconstruction of emancipatory discourse and practices from falling into the trap of reproducing, in a wider form, Eurocentric concepts and contents" (Sousa Santos 2007, p. xxvi).

The Itinerant curriculum vigorously challenges the westernized or Eurocentric conception of other knowledge as "merely" local or indigenous and therefore inadequate. It acknowledges that the westernized curriculum practiced in Nigeria is the product of socially systematized practices consisting of the deployment of diverse types of material and intellectual resources attached to specific situations and contexts. Curriculum as a daily creation was developed within some of the research groups mentioned by Paraskeva in his book as "interesting and powerful research platforms", and is considered to be a kind of itinerant and deterritorialized curriculum theory.

Three issues can be drawn from the observation that education ought to be mentally liberative. Firstly, it is a contradiction in terms to talk of education that fails to liberate the mind. Secondly, education should liberate rather than enslave the mind. Colonial epistemology fails to achieve mental liberation in Nigerian universities, and it therefore fails to promote intellectual independence and growth. Thirdly, the skills from education are the practical aspects that are relevant for society. If education lacks the practical dimension, then it fails to serve its key purpose.

Nigerian higher education institutions (HEIs) should be critical about the curriculum in use, by an examination of its theoretical and practical aspects. Theory must feed the practical, and the practical must allow further examination of theory. In other words, ideas must be tested in terms of usefulness to the community. As a result, a curriculum that relates to the community is more appropriate than a borrowed curriculum that tends to be inconsistent with community knowledge systems and experience [20]. To cross the boundaries of one's culture without realizing that the other person may have a radically different approach to reality today is no longer admissible [21]. A university should therefore use the standards of openness and dialog to assess knowledge claims without dismissing them on the basis of prejudice. The real issue, according to Giroux, is "how to democratize the schools so as to enable those groups who in large measure are divorced from or simply not represented in the curriculum to be able to produce their own representations, narrate their own stories, and engage in respectful dialogue with others". (Giroux cited in Paraskeva, 2011, p. 170).

The new curriculum should aim at making the Nigerian HEIs graduates enterprise-ready for employment and self-reliance. The indigenous culture, history, language and values must take centre stage in the new curriculum and must dominate the research projects in the system. The use of Eurocentric epistemology in African universities disrespects the epistemic concerns of students. Arguably, "many spaces within the university do not recognize the knowledge and cultural capital that first-generation students bring with them to the university as valid forms of knowledge and as valid forms of cultural capital" [16]. This gives a mismatch between the learners' epistemological background and university learning. As a result, graduates from a contradictory learning process fail to attain relevance in their own communities because there is unequal participation in the learning process. "Higher education must be made relevant to the material, historical and social realities of the communities in which universities operate" [17]. This means that all processes linked to education such as research, teaching, and learning 
must free the mind. Freeing the mind entails thinking in diverse positions that involve criticism and evaluation without any blinkers, whether imposed or acquired [19].

Fomunyam (2020) posits that education and research in higher education institutions systematically dismisses the intrinsic value of the Africa culture, language, customs, and practices from the curriculum. This implies that higher education system in Africa does not reflect the developmental problems faced by local African communities; this is also the case for Nigeria. Implementing the objectives of an itinerant curriculum will require the active participation of the Nigerian government, the education industry, inclusive of both teachers and students. Government decisions dictate the level of effectiveness and efficiency of any given public project, and this also applies in the promotion of an itinerant curriculum for higher education institutions in Nigeria. A major factor that this can be applied to is in the use of languages in these institutions of learning. As stated by Paraskeva(2011), " the official language has been imposed upon the whole population as the only legitimate language, and that it is produced and maintained not only by the authors who claim the authority to write, but by the dominant curriculum forces that codify it and the teachers whose task it is to teach based on that language." The official language as endorsed by the Nigerian government is the English language, this is very common around Africa. Out of 54 countries in Africa, 21 nations use French as their official language, 20 use English, 5 use Portuguese, and 1 use Spanish. These are all foreign languages enforced on the African populace during the colonial period (Warschaurer, 2010). In Nigeria today, English language is taught across all education levels, it is the major language of instruction. This implies that indigenous Nigerians are highly disadvantaged, and have a high possibility of ending up poorly educated, because they did not learn the 'foreigner's language'.

Asian nations have completely overhauled their education system, and this feat was achieved partly because their educational development strategies are based on their indigenous languages, thus involving their whole population and not a few elites in their strides to develop themselves and, advance technologically within their cultural framework. China for example has made Mandarin a language of educational verisimilitude (Kehdinga, 2019). Language is not just a method of human communication amongst certain people; it is also a carrier of culture, values, dreams and the aspirations of these people. Nigeria alone boasts of over 520 indigenous languages, but the curriculum used by most higher education institutions is designed in English which is also used as their medium of instruction, and this has led to the further collapse of indigenous languages. Rather than attempting to translate the European curriculum into Nigerian languages, higher education institutions in Nigeria should include authentic oral texts from each local tradition (Kehdinga, 2019;
Kebongo, 2015).

The curriculum has to be interrogated in terms of relevance and appropriateness for knowledge embedded in indigenous technologies and cultural practices. The itinerant curriculum should challenge the rhetoric of scientific supremacy in the Nigerian public education, analyse other epistemologies, craft another way through its dialectical teaching and learning. Teachers should stop the continued cycle of inferiority, suppressing student's cultural identities, and teaching them to appreciate the language and culture the way the academia sees fit, and not what is obtainable from their own native culture. Odora Hoppers (2001) argues that, "Subject contents are dumped onto children without any efforts to ensure that they first understand the subject in relation to their lived reality, a reality in which what is to be acquired via the school may only be a small part... all the disciplines crucial to national development such as science, law, sociology and political science are not anchored in, or linked in any culture but the western one. Where Africa culture is brought up(often in passing), it is presented as devoid of any epistemological content. This produces cognitive injustice". Finally, students must be seen beyond market values and given space to find the enunciatory potential of education that will help continue the struggle for social and cognitive justice.

\section{Conclusion and Recommendation}

The goal in scrapping the old and adopting a new curriculum for Nigerian HEIs is aimed at relating the activities of higher institutions mainly to the social and economic needs and day-to-day life of the people, thereby providing the requirements of industry, commerce and society. The quality of the universities' graduates and research output in relation to the expectations of local employers of labour and the organisations that should commercialise research findings, are far from fulfilling the needs of society. Therefore, this paper submits that an urgent rethink on the curriculum of Nigerian university education system offers up the itinerant curriculum. To achieve this, the curriculum currently utilized by higher institutions of learning will have to undergo three phases, first is a redesign, second is the implementation phase, and lastly, the phase of improvement. Redesigning will involve championing the struggle against the epistemicides in curriculum, teaching, and learning. This phase is primarily concerned with identifying the objectives of the curriculum, and developing one that can achieve these objectives. The major objective is ensuring that the curriculum no longer dismisses the intrinsic value of Nigerian culture, language, customs, and practices. The curriculum utilized by higher education institutions in Nigeria should therefore be infused with the wealth of knowledge that emanates from its local environment, and is appropriated towards human 
centered development.

The implementation phase involves delivering the content of the itinerant curriculum. The integration of all bodies of knowledge is the hallmark of an itinerant curriculum, and this is a pointer to the utilization of indigenous knowledge systems. For the implementation phase to be successfully piloted, the use of Nigerian Indegenous languages in the teaching and learning processes at these institutions takes the front seat. This will ensure that both educators and learners gain confidence in their own capabilities, and have a sense of pride in their own ways of being in the world. The final phase which is improvement simply involves identifying changes that must be made to align the observed outcomes with the curriculum objectives. This involves evaluating the effectiveness of the redesigned curriculum, determining if these objectives have been attained, if the intended results are achieved, and introducing modifications to improve the curriculum if not.

This paper recommends the adoption of the itinerant curriculum to ensure the Nigerian HEI curricula will be a daily creation that is constantly evolving and adjusting on a daily basis to meet societal needs, it should be fluid and not a finished, fixed or completed product. The itinerant curriculum eliminates the idea that different knowledge circulating in HEIs can be separated, classified, and hierarchized. All indigenous knowledge will be given the same priority as westernized information and viewed as relevant and an integral part of solving Nigeria's economic problems. The ideology stems from the belief that in order to resolve a problem one must understand its origin and root cause to effectively proffer solutions. This paper suggests the adoption and prioritization of a mixed and more indigenous curriculum by curriculum study researchers in collaboration with professionals in practice to reflect the Nigerian situation as the key to finding lasting solutions to inherent economic and societal issues. The shift from an Eurocentric to a more representative curriculum reflecting Nigerian history, events, culture, values, beliefs and challenges will ensure thorough research and brainstorming that will generate relatable and realistic ideas on how to tackle local challenges in the long term.

\section{Recommendation for Further Studies}

This study suggests that curriculum study researchers in devising a regularly changing curriculum, test-run a contributory/input curricula system where they partner with professionals and students in a feedback-voting method that allows students suggest course topics to be taught and discussed based on their research of current and relevant trends in their course of study while professionals in the field also make topic recommendations based on real world situations and challenges encountered in the daily execution of their jobs.

\section{REFERENCES}

[1] Agwu, E. The Guardian (2018) The Nigerian archaic academic curriculum and the need for a review. Retrieved from: https://www.google.com/amp/s/guardian.ng/features/ education/the-nigerian-archaic-academic-curriculum-and-th e-need-for-a-review/

[2] Ahmad, A. (2008). In theory. London: Verso.

[3] Ani, Ndubisi (2013) Appraisal of African Epistemology in the Global System. Retrieved from: https://www.researchgate.net/publication/290325267 Appr aisal_of_African_Epistemology_in_the_Global_System

[4] Auge, M. (2003). Não-lugares: Introdução a uma antropologia da supermoderni- dade. Campinas: Papirus Editora.

[5] Curriculum (2014), The Glossary of Education Reform. Retrieved from: https://www.edglossary.org/curriculum/

[6] Deleuze, G. \& Guattari, F. (1987). A thousand plateaus. Capitalism and schizophrenia.

[7] Eneh, O. (2015) Rethinking the Curriculum of Nigerian University Education: Functionality Challenges. Retrieved from: https://www.researchgate.net/publication/281460923 RETHINKING THE CURRICULUM OF NIGERIAN UUNIVERSITY EDUCATION FUNCTIONĀLITY CHA LLENGES

[8] Fomunyam, G. (2019) Theorising the Open curriculum as pathway to Responsiveness to in South African higher education. Retrieved from: Kehdingahttps://www.dpublicati on.com/wp-content/uploads/2019/07/19-9029.pdf

[9] Fomunyam, K.G. (2020). Theorising the Itinerant Curriculum as the Pathway to Relevance in African Higher Education in the Era of the Fourth Industrial Revolution. International Journal of Education and Practice, 8(2): 248-256.

[10] Gwaravanda, E. (2019). An Epistemological Critique of the African University Education System. Retrieved from: https://www.intechopen.com/online-first/an-epistemologica 1-critique-of-the-african-university-education-system

[11] Giroux, H. (2011). Zombie politics in the age of casino capitalism. New York: Peter Lang.

[12] Gough, N. (2000). Locating curriculum studies in the global village. Journal of Curriculum Studies, 32(2), 329-42.

[13] Jupp, J. C. \& Espinosa-Dulanto, M. (2017). Beyond US-centered multicultural foundations on race. International Journal of Multicultural Education, 19(2), 20- 43.

[14] Kehdinga, G.F. (2019). Theorising Decolonisation, Globalisation and Internationalisation in Higher Education. In the Book Titled "Decolonising Higher Education in the Era of Globalisation and Internationalisation." Sun Media Bloemfontein ISBN 978-1928424-26-0

[15] Kazeem, Y Quartz Africa. (2017) Only one in four Nigerians 
applying to university will get a spot. Retrieved from: https://qz.com/africa/915618/only-one-in-four-nigerians-ap plying-to-university-will-get-a-spot/

[16] LBS Insight (2019) The Nigerian archaic academic curriculum and the need for a review. retrieved from: https://www.lbs.edu.ng/lbsinsight/the-nigerian-archaic-acad emic-curriculum-and-the-need-for-a-review/

[17] Moreira, M. A. (2017). 'And the linguistic minorities suffer what they must?': A review of Conflicts in curriculum theory through the lenses of language teacher education. Journal of the American Association for the Advancement of Curriculum Studies, 12(1), 1-17.

[18] O'Brien, M. and Penna, S. (1999) Theorizing welfare. London: Sage.

[19] Odora Hoppers, C. (2001). Indigenous Knowledge Systems and Academic Institutions in South Africa. Perspectives in Education, 19(1): 73-85.

[20] Oliveira, I. B. (2017). Itinerant curriculum theory against epistemicides: A dialogue between the thinking of Santos and Paraskeva. Journal of the American Association for the Advancement of Curriculum Studies, 12(1), 1-22.

[21] Oliviera, I (2016) Itinerant Curriculum Theory Against Epistemicides: A Dialogue between the Thinking of Santos AND Paraskeva. Retrieved from:https://ojs.library.ubc.ca/in dex.php/jaaacs/article/view/189708/186722

[22] Paraskeva, J. M. (2011). Conflicts in Curriculum Theory: Challenging Hegemonic Epistemologies. New York: Palgrave Macmillian.

[23] Paraskeva, O. (2017) Itinerant Curriculum Theory: Visited on a Non-Theoricide.

[24] Towards the Canonicide: Addressing the Curriculum Involution. retrieved from: https://www.researchgate.net/pu blication/319325459 ITINERANT CURRICULUM THE ORY REVISITED ŌN A NON-T̄HEORICIDE TŌWA RDS THE CANONICIDE ADDRESSING THE \%27C URRICULÜM INVOLUTION\%27? enrichI $\bar{d}=$ rgreq- 66 a 80 8142c5f8e94573441 ec00366f3c-XXX\&enrichSource $=\mathrm{Y} 29$ 2ZXJQYWdlOzMxOTMyNTQ1OTtBUzo4MTE0NTE5NT g2OTM4ODhAMTU3MDQ3NjYzMTAxOQ\%3D\%3D\&el $=1 \_$× $2 \& \_$esc $=$publicationCoverPdf

[25] Paraskeva, J. (2017) Against the Epistemicide. Itinerant Curriculum Theory and the Reiteration of an Epistemology of Liberation. Retrieved from: https://link.springer.com/cha pter/10.1007/978-3-319-58650-2_4
[26] Price, T (2017) Welcome to the New Taylorism! Teacher Education Meets Itinerant Curriculum Theory. Journal of the American Association for the Advancement of Curriculum Studies, 12(1), 1-12. Retrieved from: https://digitalcommon s.nl.edu/faculty_publications $/ 88 /$.

[27] Paraskeva, Joao M. (2016) Epistemicides: Toward and Itinerant Curriculum Theory," pp. 261-289 in Joao M. Paraskeva and Shirley R. Steinberg, eds., Curriculum: Decanonizing the Field. New York: Peter Lang, 2016.

[28] Sousa Santos, B. (2003). Prefácio. In Boaventura de Sousa Santos (org.) De- mocarizar a democracia - Os caminhos da democracia participativa (pp. 25-33). Porto: Edições Afrontamento.

[29] Sousa Santos, B. (2007). Beyond abyssal thinking. From global lines to ecologies of knowledges, Review, 30(1), 45 89.

[30] Stephen, M (2020). How many universities are in Nigeria? Retrieved from: https://www.naijahomebased.com/numberof-universities-in-nigeria/

[31] Süssekind, Maria Luiza. (2014). Why Deterritorialized Curriculum? Transnational Curriculum Inquiry volume (2) http://nitinat.library.ubc.ca/ojs/index.php/tci <access date>

[32] Süssekind, M. L. (2017). Against epistemological fascism: The (self) critique of the criticals - A reading of Paraskeva's itinerant curriculum theory. Journal of the American Association for the Advancement of Curriculum Studies, 12(1), 1-18.

[33] Tse Tung, M. (2007). Oppose book worship. In S. Žižek. Slavoj Žižek presents Mao on practice and contradiction (pp. 43-51). London: Verso.

[34] TVC News (2020) ASUU strike: Union, FG fail to reach agreement. retrieved from: https://www.tvcnews.tv/asuu-str ike-union-fg-fail-to-reach-agreement/

[35] WES Staff (2017) Education in Nigeria. Retrieved from: https://wenr.wes.org/2017/03/education-in-nigeria

[36] World Population Review (2020). Retrieved from: https://worldpopulationreview.com/countries/nigeria-popul ation/

[37] Uleanya, C. Rugbeer, Y. Duma M. (2018) Localizing Educational Curriculum of Tertiary Institutions: Approach to Sustainable Development. Retrieved from: https://www.abacademies.org/articles/localizing-educationa 1-curriculum-of-tertiary-institutions-approach-to-sustainable -development-7232.html 